\title{
Relacionamento e fidelização entre agricultores e consumidores em grupos de venda direta de alimentos agroecológicos em Florianópolis-SC
}

\author{
Relationship and loyalty between farmers and consumers in direct selling groups \\ of agroecological foods in Florianópolis-SC
}

Amanda Biesek Lovatto ${ }^{1}$ (D), Dayana Lilian Rosa Miranda² (D), Oscar José Rover ${ }^{3}$ (D), Alberto Bracagioli Neto ${ }^{1}$ (D)

Universidade Federal do Rio Grande do Sul (UFRGS), Porto Alegre (RS), Brasil. E-mails: amandablovatto@gmail.com;
abracagioli@gmail.com
²Universidade Federal do Paraná (UFPR), Curitiba (PR), Brasil. E-mail: dayana.I.rosa@gmail.com
${ }^{3}$ Universidade Federal de Santa Catarina (UFSC), Florianópolis (SC), Brasil. E-mail: oscar.rover@gmail.com

Como citar: Lovatto, A. B., Miranda, D. L. R., Rover, O. J., \& Bracagioli Neto, A. (2021). Relacionamento e fidelização entre agricultores e consumidores em grupos de venda direta de alimentos agroecológicos em Florianópolis-SC. Revista de Economia e Sociologia Rural, 59(3), e227676. https://doi.org/10.1590/1806-9479.2021.227676

\begin{abstract}
Resumo: Nas últimas décadas surgiram movimentos contrários ao modelo agroalimentar hegemônico, que prezam pelos valores de qualidade, tradição, confiança e proximidade, geralmente baseados em circuitos curtos de comercialização. Este artigo analisa o relacionamento entre agricultores e consumidores e a fidelização destes, adotando a abordagem do marketing de relacionamento, em grupos de venda direta denominados células de consumidores responsáveis (CCR). A metodologia utilizada nesta pesquisa incluiu observação participante, aplicação de questionários e acompanhamento de trabalho da equipe institucional. Identificou-se que as esferas da produção e do consumo avançaram e mostraram-se interessadas no estreitamento de relações, embora ainda haja afastamento entre ambas. Os consumidores apresentaram um nível crescente de conscientização sobre suas ações quanto ao consumo alimentar responsável e manifestaram satisfação, comprometimento e fidelidade à iniciativa. Conclui-se que o projeto das CCR é um ambiente em potencial para ampliar ações e análises do marketing de relacionamento e de corresponsabilização entre consumidores e agricultores.
\end{abstract}

Palavras-chave: circuitos curtos de comercialização, marketing de relacionamento, fidelidade de consumidores, produto orgânico.

\begin{abstract}
In the last decades, movements contrary to the hegemonic agri-food model have emerged. These movements foment values such as quality, tradition, trust, and proximity, usually based on short food supply chains. This article analyzes the relationship between farmers and consumers and the latter's loyalty to Célula de Consumidores Responsáveis (CCR) (Responsible Consumption Cells), a direct selling group. To carry out the analysis, the relationship marketing approach was adopted. The methodological tools used in this research were participant observation, questionnaire surveys, and work monitoring of the institutional team. It was identified that there is an interest in narrowing the gap between the spheres of production and consumption, although there is still a distance between them. The consumers presented a growing level of awareness regarding responsible food consumption, expressing satisfaction, commitment, and loyalty to the initiative. It was concluded that the CCR project has the potential to broaden actions and analyzes of relationship marketing, and co-responsibility between consumers and farmers.
\end{abstract}

Keywords: short food supply chains, relationship marketing, consumer loyalty, organic product. 


\section{Introdução}

As células de consumidores responsáveis (CCR) são alternativas de abastecimento e venda direta de alimentos orgânicos/agroecológicos ${ }^{1}$ por meio de pedidos antecipados em cestas fechadas. O projeto é desenvolvido pelo Laboratório de Comercialização da Agricultura Familiar (Lacaf/UFSC) e envolve mais de 400 consumidores ativos, em 11 grupos de consumo (células) e cinco grupos de agricultores e suas famílias. Essa experiência foi criada em outubro de 2017 e tem como uma de suas inspirações os Gruppi di Acquisto Solidale (GAS), originários na Itália. O objetivo dela é gerar dinâmicas de mercado e consumo ético/responsável que ampliem o abastecimento de alimentos oriundos da agricultura familiar na forma de cadeias curtas (Gazolla \& Schneider, 2017).

O estado de Santa Catarina, localizado na região Sul do Brasil, possui uma estimativa de 7 milhões de habitantes, dos quais cerca de 16\% vivem no meio rural (Instituto Brasileiro de Geografia e Estatística, 2018a). A agricultura familiar, de acordo com a definição da Lei no 11.326/06 (Brasil, 2006), predomina no estado, uma vez que corresponde a aproximadamente $87 \%$ dos estabelecimentos (França et al., 2009). A diversificação da produção desses agricultores potencializa a biodiversidade e os processos de conversão agroecológica. Florianópolis, capital de Santa Catarina, apresenta uma estimativa de 492.977 habitantes (Instituto Brasileiro de Geografia e Estatística, 2018b), onde há poucas terras agricultáveis, uma vez que, entre as principais atividades que compõem a economia atual, predominam o turismo, a tecnologia de informação, o comércio e a prestação de serviços (Florianópolis, 2019), caracterizando-se como um grande centro consumidor pela sua concentração e expansão urbana.

A comercialização de alimentos orgânicos oriundos da agricultura familiar (AF) catarinense se deu, predominantemente, na primeira década deste século, por meio de mercados regionais com venda direta ao consumidor (como feiras e lojas), mesmo que já houvesse uma comercialização significativa em supermercados (Zoldan \& Mior, 2012). Mais recente e especificamente no caso da venda no varejo de Florianópolis, os alimentos orgânicos têm sido comercializados por meio de variados canais de comercialização, como feiras, sacolões, pequenos mercados de bairro, supermercados ou lojas especializadas. Contudo, os supermercados respondem por grande parcela dessa comercialização (Gelbcke et al., 2019).

A comercialização de alimentos orgânicos vem crescendo mundialmente, inclusive no Brasil, onde as taxas chegaram a 32,5\% em 2016 (Organics Brasil, 2016). De acordo com o jornal Sul 21 (2019), a Federação Internacional de Movimentos da Agricultura Orgânica (Ifoam) recentemente identificou cerca de 3 milhões de produtores orgânicos em 181 países e o Conselho Brasileiro da Produção Orgânica e Sustentável (Organis), que reúne cerca de 60 empresas do setor, apontou o Brasil como líder do mercado de orgânicos da América Latina. O crescimento do mercado de orgânicos se deve ao fato de que se tornou interessante também às grandes corporações, não ficando restrito aos agricultores familiares. Tal fenômeno ficou conhecido como "convencionalização da agricultura orgânica" (Buck et al., 1997; Guthman, 2004) e traz consigo problemáticas que podem afetar esses agricultores, excluindo socioeconomicamente os menos capitalizados e fragilizando os princípios agroecológicos.

Nas últimas décadas surgiu um processo denominado de "virada para a qualidade", no qual os valores de qualidade, tradição, confiança e proximidade têm promovido novas dinâmicas agroalimentares. O que se verifica é uma mudança de modos industriais de produção e suas convenções de qualidade, altamente padronizadas e operadas na lógica de produção em massa de mercadorias, para movimentos que valorizam processos de (re)localização, produção artesanal e diferenciação dos produtos (Goodman \& Goodman, 2009), além de retomar a centralidade do alimento para a vida e sociedades humanas (Birochi et al., 2019). Nesse sentido, avançam iniciativas que buscam a aproximação entre agricultores e consumidores para o desenvolvimento de alternativas de comercialização e

\footnotetext{
1 Optou-se por utilizar a expressão "orgânicos/agroecológicos" ao reportar-se a um alimento ou produto que está em conformidade com a Lei brasileira de Orgânicos no 10.831 e que abrange os princípios agroecológicos nos seus aspectos socioprodutivos.
} 
promoção de inovações sociais no ramo agroalimentar (Portilho, 2009; Darolt, 2013; Preiss et al., 2017). De acordo com Gliessman \& Rosemeyer (2009), a agroecologia, como prática social, tem como um de seus princípios a aproximação entre as esferas da produção e do consumo, tornando-a grande impulsionadora de novas estratégias para contribuir na promoção de novos sistemas produtivos e de abastecimento.

Em uma perspectiva agroecológica, a atividade de um agricultor não se resume à produção, implicando também seu envolvimento no processo de comercialização, mesmo que mediada por meio de suas organizações. Nesse contexto, os arranjos de venda direta de alimentos orgânicos/agroecológicos, como as CCR, com o marketing de relacionamento, configuram-se como ferramentas para o desenvolvimento da agricultura familiar, em especial a de base agroecológica. Isso porque o aumento da proximidade com os consumidores, com base nas experiências geradas no projeto das CCR, permite que os agricultores constituam estratégias autônomas de marketing, buscando a fidelização de mercado e garantindo seu lugar nesse canal comercial.

A pesquisa foi realizada com o objetivo de identificar como se desenvolveu o relacionamento entre agricultores e consumidores na história das $C C R$, analisando aspectos de responsabilização, fidelização e satisfação dos consumidores com essa forma de venda direta.

\section{Fundamentação teórica}

A construção de alternativas de comercialização de alimentos, ao contrário dos processos de desterritorialização, artificialização, padronização e oligopolização da produção e do consumo alimentar, vem criando importância significativa para grupos sociais (Niederle, 2013). De acordo com Zamberlan et al. (2008), a explicação de tal fenômeno se fundamenta no aumento da preocupação dos consumidores com a segurança alimentar e o meio ambiente. A proposta dessas formas alternativas de comercialização é que as pessoas, as comunidades e o próprio Estado assumam a responsabilidade pelas práticas de produção, distribuição e consumo dos alimentos.

Dados do Instituto Brasileiro de Defesa do Consumidor (2012) apontam que as vendas diretas são mais acentuadas onde a agricultura familiar está presente, principalmente para produtos orgânicos/agroecológicos. De acordo com Fantini et al. (2018), isso indica que a expansão e a consolidação da demanda por produtos orgânicos, que aumentaram cerca de $20 \%$ ao ano na última década (IPD Orgânicos, 2011), podem se enriquecer vigorosamente da maior proximidade, do conhecimento e da confiança entre agricultores e consumidores. Isto vem potencializando a formação de circuitos curtos de comercialização (CCC) de alimentos.

Segundo Darolt et al. (2013), os CCC são classificados em vendas direta e indireta, sendo a primeira realizada em contato direto com o consumidor e a segunda efetuada por meio de um único intermediário. Já que as CCR caracterizam-se como uma forma de venda direta, observa-se que a iniciativa promove: a competitividade econômica da agricultura familiar, mediante a construção de preços justos, que se expressam numa melhor remuneração ao agricultor e um preço acessível ao consumidor; o aumento da oferta e da demanda local de alimentos; a diversidade da produção e do mercado.

Nesse sentido, CCC que dão foco no marketing de relacionamento apresentam-se como uma alternativa estratégica para a agricultura familiar. De acordo com Kotler \& Armstrong (2007), o conceito atual do marketing diz que o objetivo estratégico mais importante dos produtores não é vender, mas constituir uma relação de confiança duradoura. Nos CCC, essa confiança faz parte do processo de fidelização dos consumidores e pode estar associada à sua satisfação, assim como a outros fatores que contribuem com o seu nível de responsabilização e comprometimento.

Em síntese, os canais de abastecimento que compõem CCC de alimentos, como as CCR, aliados à utilização do marketing para a AF, podem aumentar o grau de relacionamento entre o agricultor e o consumidor. Isso promove, para além da fidelização, uma mudança nos regimes de responsabilização (accountability) no sistema agroalimentar. 


\subsection{Marketing de relacionamento}

O conceito de marketing de relacionamento afirma que a confiança entre o vendedor e o comprador é de suma importância para a consolidação de qualquer organização ou empresa no mercado (Kotler \& Armstrong, 2007). Segundo os autores, tal explicação se baseia na chamada teoria dos 4Ps, a qual consiste em estratégias voltadas a quatro componentes distintos: produto, preço, publicidade e praça. As estratégias direcionadas aos 4Ps do marketing são válidas para qualquer setor produtivo, sendo também cruciais para a expansão e a consolidação da agricultura familiar, especialmente para a de base agroecológica (Fantini et al., 2018).

O marketing de relacionamento é uma expressão criada por Berry (2001) na literatura do marketing de serviços, que tem como princípio a gestão estratégica do relacionamento, objetivando a fidelização do consumidor. Tal abordagem teórica inclina-se para a vertente do consumo, com a construção de relacionamentos em longo prazo. Isso porque se baseia no estreitamento das relações, no sentido de atrair, manter e aumentar o relacionamento, bem como despertar mais consciência sobre a responsabilização de quem compra sobre o que está sendo consumido e os modos de produção envolvidos. Trazendo essa abordagem para o contexto das CCR, os consumidores passariam a ser parte do processo de gestão da organização, criando vínculos com os agricultores, ao mesmo tempo que se tornam "coprodutores". De acordo com o movimento Slow food², essa expressão é a conscientização do ato do consumo, ou seja, a responsabilização do consumidor pelo ciclo produtivo do alimento, dado que o coprodutor orienta o mercado e a produção por meio de suas escolhas, assumindo um novo papel no processo, quando se torna consciente de suas ações (Petrini, 2009).

As ações para que os agricultores saibam se posicionar quanto à comercialização têm crescido muito, visto que esse fator é determinante na articulação com os segmentos "pré e pós-porteira", assim como com práticas de gestão do processo produtivo. Nesse sentido, torna-se importante analisar estratégias para inserir a AF nos mercados, procurando melhorar as condições de competitividade ante os avanços do sistema de grande distribuição de alimentos, que representa mercados globalizados e cada vez mais concorrenciais (Fantini et al., 2018). Segundo esses autores, a precificação, a distribuição, a publicidade e a comunicação deveriam ser incorporadas à gestão dos estabelecimentos e das organizações da AF. Aprimorando tais elementos estratégicos, poder-se-ia evitar que outros atores do mercado comprassem mercadorias dos produtores e se beneficiassem as revendendo com margens que retiram ganhos dos agricultores e geram assimetria de poder de negociação.

Do ponto de vista histórico, o regime de responsabilização no setor agroalimentar passou de familiar às comunidades; sendo repassado para o Estado com a chegada da industrialização e urbanização e, atualmente, é dominado pelas grandes corporações regidas pelo capital financeiro (Niederle, 2013). O mesmo vem acontecendo com a agricultura orgânica, que mesmo parcialmente faz parte desse grande sistema de distribuição de alimentos. Sua convencionalização (Buck et al., 1997; Guthman, 2004) traz consigo uma série de elementos que dificultam a participação dos agricultores familiares no setor, como a dependência de centrais atacadistas para se inserir nos mercados (Viegas, 2016) e a distribuição desses alimentos em cadeias longas de comercialização. Quando operada por Grandes estruturas de distribuição, a cadeia de orgânicos se assemelha às lógicas operadas na produção convencional, estimulando grandes escalas e a dependência de insumos. Ainda, os custos de certificação e os preços elevados praticados por redes de supermercados restringem o acesso aos orgânicos a consumidores mais capitalizados (Goodman \& Goodman, 2009). Os CCC e formas de venda direta como as CCR estimulam a proximidade entre produtores e consumidores, gerando potenciais para uma produção agroecológica diversificada e sua venda a preços acessíveis.

\footnotetext{
2 Fundado em 1989, o movimento Slow food foi criado inicialmente como uma proposta de oposição ao fast food e ao modo de vida representado pelo modelo, propondo a desaceleração, o retorno à convivialidade e ao direito do prazer de saborear um bom prato. A partir desse ideal, cresceu e acabou se tornando uma associação internacional presente em 132 países, promovendo pequenos produtores, defendendo a biodiversidade e preservando culturas, sabores e saberes locais.
} 
Tem sido proposto que para a agricultura familiar agroecológica se tornar competitiva, deve usar o marketing de relacionamento como ferramenta. Isso porque, em geral, os produtos agroecológicos ofertados no mercado tendem a não ser padronizados, fazendo com que na venda direta, em que há contato de produtores com consumidores, se construam relações de confiança (Fantini et al., 2018). Considera-se que é dessa forma que eles podem trocar conhecimentos e manter uma relação de proximidade, incorporando valores imateriais aos alimentos, como a informação, a reputação, a troca de saberes e até a amizade (Marescotti, 2006). Além disso, a venda direta possibilita um preço mais justo ${ }^{3}$ pago pelo alimento orgânico/agroecológico se comparado com o dos supermercados, já que não há intermediários na cadeia produtiva, gerando mais renda para o produtor.

Nessa perspectiva, o caso das CCR apresenta-se como uma alternativa de comercialização direta de alimentos, ou CCC. A tecnologia social, que se iniciou ao final de 2017, vem ganhando expressiva visibilidade ao contribuir na promoção de relações mais próximas e autogeridas entre agricultores e consumidores, na valorização dos saberes, da cultura e da diversificação produtiva, revelando um ambiente favorável para o desenvolvimento de ações de marketing de relacionamento.

\subsection{Satisfação e fidelidade de consumidores}

Atualmente, o mercado consumidor é um importante elemento regulador dos planos estratégicos dos estabelecimentos produtores. Assim, o esclarecimento dos fatores que induzem a fidelidade dos consumidores é de suma importância para organizações como as CCR. Como dito anteriormente, é interessante que os agricultores familiares incorporem estratégias para permanecer no mercado. A ideia do marketing de relacionamento integra a aproximação entre consumidores e agricultores, sendo importante procurar ações que os satisfaçam e os tornem fiéis, a fim de manter essa relação de proximidade e de trocas.

A qualidade é um fator importante na discussão sobre satisfação e fidelidade de consumidores, visto que tem influência direta sobre esses aspectos. Conforme citado por Johnson et al. (2001), a qualidade participa de todos os modelos de índices de satisfação dos consumidores como uma variável que tem influência direta sobre esse fator. Segundo Vavra (1997), a satisfação mede precisamente a opinião dos consumidores a respeito de dada organização, apontando que trabalha voltada à qualidade, de forma que os consumidores se disponibilizem a recomendá-la a outras pessoas.

Para analisar a satisfação, há duas definições propostas por Vavra (1997): uma como resultado e outra como processo. A primeira considera o estado resultante da experiência de consumo; a segunda enfatiza a percepção, a evolução e os processos psicológicos que favorecem a satisfação. Fornell (1992) afirma que clientes fiéis não são necessariamente clientes satisfeitos, mas os clientes satisfeitos tendem a ser fiéis. Para ele, há outras formas de retenção dos consumidores que não sejam somente pela satisfação. Rodrigues (2006) acrescenta que o conceito de satisfação pode ser entendido pela rede de valores que participam do processo de compra e que esta é influenciada positiva ou negativamente conforme a percepção do consumidor após o consumo.

Sobre o conceito de fidelidade, pode-se verificar que diversos autores mencionam uma correlação forte entre recompra e fidelidade do consumidor (Baloglu, 2002; Bendapudi \& Berry, 1997; Johnson \& Fornell, 1991; Vavra, 1997). Johnson e Fornell (1991) dizem que o que faz um consumidor ser fiel é somente a tendência de recompra em uma mesma empresa. Porém, esse fator é motivado por diversos outros elementos, o que torna a análise bastante complexa. Baloglu (2002) acrescenta o comportamento de recompra e a atitude de comprometimento dos consumidores como parâmetros que auxiliam a entender a fidelidade a uma organização, considerando que um fator não prossegue sem o outro. Aqui, torna-se interessante analisar o que os fariam permanecer comprando e o que os fariam desistir. Ainda, para Bendapudi e Berry (1997), o relacionamento entre clientes e fornecedores também está atrelado ao comportamento de fidelidade do consumidor. Este, segundo os

\footnotetext{
${ }^{3}$ Define-se como justo um preço que seja acessível (em relação ao mercado dos orgânicos como um todo) para os
} consumidores, sem comprometer a renda aos produtores. 
autores, pode basear-se em dois padrões: o grupo de consumidores que tem vontade de continuar a se relacionar com os fornecedores por motivos econômicos e o grupo que se dedica a manter uma relação por razões afetivas e psicológicas.

\section{O caso das células de consumidores responsáveis (CCR) em Florianópolis (SC)}

As CCR são arranjos de venda direta e coletiva de alimentos orgânicos/agroecológicos oriundos da agricultura familiar, por meio de pedidos antecipados e cestas fechadas. Buscam gerar dinâmicas de mercado e consumo ético/responsável que ampliam o abastecimento desses alimentos, além de possibilitar a aproximação entre os consumidores e os agricultores, estabelecendo a corresponsabilização entre as partes. Consistem em uma alternativa de compra desses alimentos a preços justos, pois trabalham com preços abaixo dos praticados nos demais canais de comercialização de orgânicos encontrados em Florianópolis (Universidade Federal de Santa Catarina, 2019).

O projeto operado nesse modelo foi criado em outubro de 2017, sendo uma experiência recente, mas que já vem demonstrando significativa representatividade, considerando o expressivo crescimento e a capacidade de multiplicação. Atualmente, encontram-se em operação 11 CCR com mais de 400 famílias de consumidores, abastecidas por cinco grupos de agricultores (54 famílias) vinculados à Rede Ecovida de Agroecologia. Cada CCR possui um ponto de entrega específico na Grande Florianópolis, no qual os agricultores entregam e os consumidores retiram os alimentos.

O funcionamento das CCR ocorre via entregas semanais de cestas fechadas, montadas pelos agricultores. A coletividade desse arranjo de venda direta se dá por meio da organização dos agricultores em grupos, sendo cada CCR também formada por um grupo de consumidores, tendo cada qual uma coordenação. Cada grupo de agricultores abastece entre uma e três CCR diferentes. O meio de comunicação entre as partes se dá via WhatsApp, espaço onde os coordenadores do grupo de agricultores e os consumidores podem se relacionar, a fim de administrar os pedidos das cestas, os pagamentos e possíveis problemas que ocorram durante o processo. Ocorre um pagamento antecipado referente a cada ciclo de cestas (mês), o qual é feito diretamente aos agricultores, via depósito bancário.

Quanto às cestas, são de dois tipos: pequeno (tamanho P) e grande (tamanho G). A primeira é composta de aproximadamente $4,5 \mathrm{~kg}$ com diversidade de nove itens, enquanto a segunda contém cerca de $9 \mathrm{~kg}$ com diversidade de 13 itens, ambas incluindo variedades de raízes, tubérculos, folhosas, frutas, verduras, legumes, chás e temperos. Ambas possuem um preço fixo semanal de $R \$ 29,00$ (P) e $R \$ 53,00$ (G), o qual se mantém desde a origem desse modelo de CCR e a diversidade dos produtos muda de acordo com a sazonalidade da produção, o que exige flexibilidade de hábitos alimentares pelos consumidores. Caso o consumidor queira outros produtos, é disponibilizada semanalmente uma lista de produtos adicionais orgânicos e coloniais (não orgânicos).

As decisões referentes a cada CCR são tomadas pelo grupo que a compõe, em reuniões presenciais ou por meio de mídias sociais, com a presença de consumidores e agricultores, tendo alguma mediação dos membros do Lacaf/UFSC. Cada CCR conta com um termo de responsabilidades compartilhado entre consumidores e agricultores, o qual firma as responsabilidades que ambos os grupos devem assumir para o devido funcionamento do processo ${ }^{4}$.

\section{Metodologia}

A pesquisa foi realizada em parceria com a equipe do Lacaf/UFSC, no período entre janeiro e março de 2019. Utilizou-se uma abordagem quali-quantitativa, em que foram aplicados dois questionários semiestruturados ${ }^{5}$, sendo o primeiro proposto a todos os consumidores das CCR e o segundo direcionado especificamente aos coordenadores do grupo de agricultores. Foram respondidos 101 questionários válidos, de um total de 240

\footnotetext{
${ }^{4}$ Mais informações sobre as CCR podem ser obtidas em https://celulasconsumo.ufsc.br/

${ }^{5} \mathrm{O}$ projeto de pesquisa foi aprovado pelo Comitê de Ética em Pesquisa com Seres Humanos da UFSC, por meio do parecer 2.657.160 e CAAE 82587718.0.0000.0121.
} 
consumidores que estavam ativos quando da realização da pesquisa de campo. Os coordenadores dos quatro grupos de agricultores que abasteciam as CCR na ocasião responderam cada qual um questionário válido. Em vias de aprofundar a compreensão da realidade de campo, foram utilizados a observação participante em saídas de campo e o acompanhamento de trabalho da equipe institucional (do Lacaf e das coordenações de agricultores e consumidores).

Nos questionários, foram preparadas questões para atender aos seguintes objetivos específicos do trabalho: i) identificar como se desenvolveu o relacionamento entre agricultores e consumidores na história das CCR; ii) identificar como se desenvolveram a responsabilização e a fidelização dos consumidores a essa forma de venda direta; iii) identificar a satisfação dos consumidores com essa forma de venda direta.

Os questionários foram elaborados pelo Google Forms ${ }^{\circledR}$ e enviados pelo grupo de WhatsApp ${ }^{\circledR}$ de cada CCR, bem como via e-mail de cadastro dos consumidores. A ferramenta do Google ${ }^{\circledR}$ auxiliou na sistematização dos dados por meio de planilhas e gráficos de respostas gerados automaticamente. No formato semiestruturado, as perguntas tenderam a ser mais direcionadas, ao mesmo tempo que os entrevistados puderam responder livremente, fornecendo resultados mais aprofundados sobre as suas opiniões (Manzato \& Santos, 2012) e garantindo o anonimato nas respostas. Assim, as perguntas foram semiabertas, deixando um espaço para comentários e/ou justificativas em cada uma.

Para a realização desta pesquisa, consideraram-se fundamental o conhecimento, a aproximação e o vínculo com o grupo de estudo. Assim, pela observação participante, foi dado foco a um grupo de agricultores que atendia a duas das oito CCR existentes na ocasião. Visitaram-se as diferentes propriedades das famílias participantes desse grupo. Além disso, acompanhou-se o trabalho da equipe do Lacaf/UFSC mediante participação em reuniões, auxílio na partilha semanal das cestas e atuação na dinâmica de cadastro. Também se realizou comunicação direta com consumidores e participou-se de algumas de suas reuniões. Conversas informais estiveram presentes durante todas as visitas, as quais permitiram entender as dificuldades e os projetos futuros relativos às CCR.

Os dados dos questionários contabilizados e fornecidos pelo próprio formulário do Google ${ }^{\circledR}$ foram interpretados com base na análise dos gráficos que ilustram dados quantitativos do estudo. Já as respostas descritivas dos agricultores e dos consumidores, que contribuem para a análise qualitativa da pesquisa, foram analisadas separadamente. Entre todas estas, foram escolhidas as respostas mais relevantes, de acordo com as palavras e/ou frases que mais apareciam relacionadas aos objetivos do estudo. Ademais, procuraram-se respostas que fossem divergentes, para melhor representar a multiplicidade de perspectivas. Finalmente, as experiências em campo da observação participante também contribuíram qualitativamente para o conjunto de reflexões em torno da análise proposta.

\section{Resultados e discussão}

Este tópico foi dividido conforme as quatro ênfases apontadas pela literatura para ampliar o marketing de relacionamento: relacionamento, responsabilização, satisfação e fidelização.

\subsection{Relacionamento}

As CCR são parte de um projeto recente no qual o relacionamento entre agricultores e consumidores ainda revela um distanciamento. Porém, isso não reflete necessariamente desinteresse dos envolvidos quanto à importância dada ao estreitamento de relações entre as esferas do consumo e da produção, uma vez que se nota um entusiasmo ao apontarem soluções e ideias para estabelecerem uma aproximação efetiva.

Grande parte das respostas indicou que o contato virtual via WhatsApp ${ }^{\circledR}$ é o mais utilizado para comunicação e relacionamento. Cada célula possui um grupo nesse meio de comunicação e quem participa são todos os consumidores (o número varia de célula para célula; na ocasião da pesquisa, a maior possuía 120 e a menor, 20 membros) e os coordenadores de agricultores (um por grupo), os quais estão ali para ajudar a gerenciá-lo, 
mas também para representar os outros agricultores. Nesse sentido, verifica-se que $85 \%$ dos consumidores responderam que têm contato somente com a coordenação dos agricultores, sendo a principal relação entre eles comercial, relacionada aos pagamentos das cestas, pedidos de produtos adicionais e informes gerais.

Percebe-se que ambas as partes almejam diminuir tal distanciamento $(70 \%$ das respostas dos consumidores e $100 \%$ dos coordenadores de agricultores), afirmando que seria muito importante o estreitamento de relações (Figura 1). Em resposta aberta a essa questão, a maioria das justificativas aponta para um consumo responsável, como se pode perceber com a seguinte afirmativa: “Onde há conhecimento, há vínculo e pode haver empatia. Acho muito importante que os consumidores conheçam a realidade dos agricultores e que os agricultores conheçam os consumidores. Pode gerar valorização mútua" (consumidor 81). Do outro lado, tem-se a seguinte declaração: "A aproximação aumenta a credibilidade dos agricultores e o engajamento dos consumidores" (coordenador de agricultores 1). Tais argumentos fazem parte do marketing de relacionamento, no sentido de construir relações de confiança entre agricultores e consumidores, como sugerido por Kotler e Armstrong (2007), o que é estimulado em circuitos curtos de comercialização.

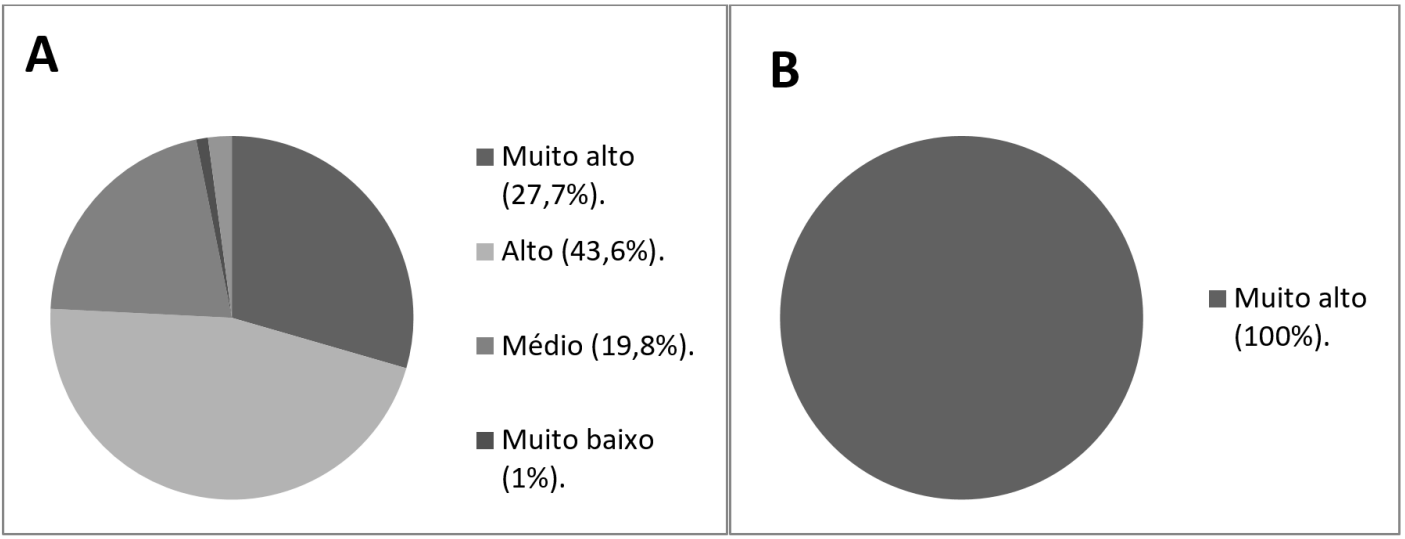

Figura 1. Nível de importância que os consumidores (A) e os coordenadores de agricultores (B) dão ao estreitamento de relações entre eles nas CCR. Fonte: elaborado pelos autores (2019).

Por outro lado, embora que minimamente, ainda se encontram respostas divergentes desse pensamento. Um agricultor pesquisado respondeu que gostaria de um intermediário gerindo as relações, alegando que há falta de tempo para se dedicar ao projeto e ainda manter contato com os outros agricultores. Somente um consumidor manifestou que "a figura do coordenador já é o suficiente, pois ele representa muito bem os outros agricultores" (consumidor 93).

Quando perguntados sobre como ampliar a relação de proximidade, em ambos os questionários se observaram respostas similares. Destacam-se as visitas às propriedades em primeiro lugar, com aprovação de todos os coordenadores de agricultores e $73 \%$ dos consumidores. Também tiveram importância as oficinas participativas, as rodas de conversa e as reuniões. Em campo, observou-se grande motivação em mobilizar-se para tal. Os consumidores se prontificaram em buscar a organização desses eventos em conjunto com os agricultores, principalmente no que se refere à culinária, pois é difícil a mudança alimentar sem informações qualificadas. Além disso, na visita às propriedades das famílias agricultoras, eles afirmam que uma relação mais próxima com os consumidores facilitaria o planejamento da produção, já que se organizam em torno da demanda de cestas mensais.

É importante ressaltar que diversos consumidores ingressaram recentemente no projeto. Assim, ainda não criaram vínculos com os agricultores para além da coordenação, porque não tiveram a oportunidade de participar de outras atividades além da partilha das cestas e do grupo de WhatsApp ${ }^{\circledR}$. Além disso, percebe-se que mesmo os consumidores que estão envolvidos há mais tempo e dizem ter participado de encontros proporcionados pelo projeto sentem necessidade de fortalecer e construir laços de trocas em ocasiões futuras. 
Tais percepções podem ser ponderadas com a afirmação de Berry (2001), para quem o marketing de relacionamento se baseia em relações de longo prazo, ou seja, ainda há um caminho a ser trilhado para alcançar mais qualidade de relacionamento entre agricultores e consumidores, mesmo que já se perceba que comparativamente às compras convencionais, os consumidores das CCR trocam mais informações sobre seus fornecedores, a procedência dos produtos e seus processos produtivos.

\subsection{Responsabilização}

$\mathrm{Na}$ denominação dada às $\mathrm{CCR}$, subentende-se que o projeto visa ampliar a responsabilização dos consumidores no processo de venda-compra direta. Dessa forma, perguntou-se aos consumidores qual era o entendimento sobre o "consumo responsável" e quais eram as ações que eles realizavam no projeto que se enquadravam nesse conceito. Algumas falas são indicativas das principais ações que eles consideram: "Compreender a proposta das CCR dentro da nossa realidade sócio-agro-histórica; "Sentir-me bem pagando o preço aos agricultores para que eles ganhem de forma justa" (consumidor 7) e "Buscar e fomentar uma alternativa aos mercados convencionais, que parta de pressupostos de uma economia solidária e agroecológica, configura um processo de responsabilização do consumo" (consumidor 56). Para Fantini et al. (2018), o envolvimento do consumidor na gestão do projeto demonstra sua responsabilidade para com este. Há diversas respostas que apontam para isso, uma vez que estão de acordo com o termo de responsabilidades compartilhadas das CCR. Isso fica evidente nas frases que mais aparecem nas respostas ao questionário: "ajudar na partilha"; "não desperdiçar alimentos"; "devolução de embalagens para serem reaproveitadas"; "levar sacolas plásticas para a partilha"; "ser assíduo com os pagamentos".

O entendimento de $64 \%$ dos consumidores sobre a sua responsabilização passa pela preocupação para com os agricultores, estendendo-se a toda a cadeia produtiva. De maneira geral, considera-se que as pessoas estão participando de um grande processo de conscientização sobre as suas ações acerca do consumo agroalimentar, por meio das CCR. Isto não exclui o fato de que muitos consumidores se inserem na iniciativa como clientes em busca da satisfação de suas necessidades individuais, isto é, sem ponderar, mais cuidadosamente, como combinar satisfação com responsabilização. Contudo, procedimentos como o pagamento mensal antecipado e a aceitação de uma cesta fechada, sem possibilidade de escolha de cada produto, já revelam um grau de disposição dos consumidores das CCR a mais responsabilização. Além disso, muitas respostas indicam que o envolvimento na dinâmica organizativa das CCR tem produzido revisões em suas percepções quanto ao seu papel como consumidores de alimentos orgânicos/agroecológicos produzidos por agricultores familiares.

\subsection{Satisfação}

Sabe-se que a satisfação influencia o processo de fidelização dos consumidores e que este é um dos principais objetivos do marketing de relacionamento. Vavra (1997) sugere duas definições para analisar a satisfação: uma como resultado e outra como processo. Assim, procurou-se analisar os questionários dos consumidores quanto à satisfação para enquadrálos nessas duas definições.

Em relação ao primeiro aspecto referente ao enfoque no resultado da experiência, a pesquisa indica alta satisfação das pessoas (97\%), uma vez que essa foi a proporção de entrevistados que classificaram a experiência como "muito boa" e "boa" (Figura 2). Os aspectos mais citados para justificar essa satisfação são: (i) alimentos de qualidade, saudáveis e diversificados; (ii) preço; (iii) informações dos produtos; (iv) estímulo a reflexões. Observase que as principais justificações de satisfação como resultado vêm de dois campos: um relacionado à qualidade dos alimentos e outro relacionado ao relacionamento que oportuniza informações e reflexões. 


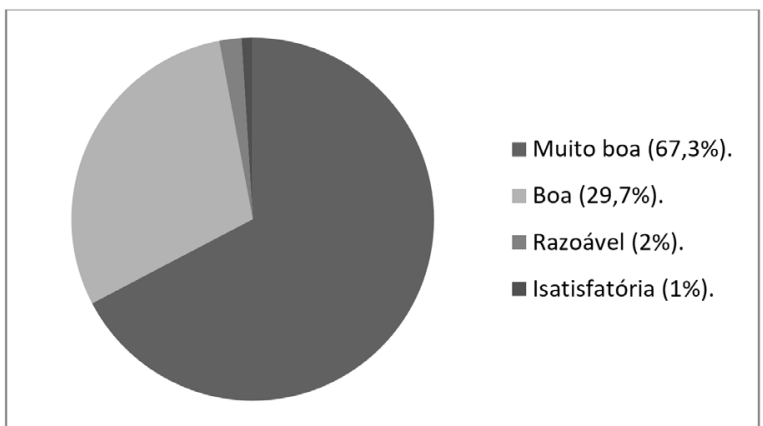

Figura 2. Nível de satisfação dos consumidores quanto à sua experiência no projeto das CCR. Fonte: elaborado pelos autores (2019).

Verificou-se que a satisfação analisada como parte de um processo também está presente, em que elementos como confiança, aprendizado e ampliação de relações sociais são citados. Nesse sentido, respostas como as seguintes ilustram essa ideia: "A melhor experiência é a confiança e saber que o produtor é parte muito importante neste processo" (consumidor 68); "Estou aprendendo muito sobre a produção e sobre os alimentos. As relações estimulam a cooperação e circulação de informações relevantes" (consumidor 73).

Entende-se que o projeto das CCR tem uma organização voltada para a satisfação, tanto como resultado quanto como processo. Isso porque, como visto anteriormente, a maioria das pessoas (97\%) está satisfeita com aspectos como o preço e a qualidade dos produtos, bem como com as experiências que proporcionam confiança e novos aprendizados entre os agricultores e consumidores.

\subsection{Fidelidade}

A fidelização dos consumidores está diretamente atrelada a ações de marketing de relacionamento, visto que se propõem relações de longo prazo para validá-la. Sobretudo, associam-se à fidelização níveis de relacionamento, de responsabilização e atitudes de comprometimento, por sua vez, tão importantes quanto a satisfação do consumidor. 0 comportamento de recompra também se aplica às CCR, uma vez que mensalmente o consumidor decide se fará o pagamento antecipado de quatro cestas referentes ao mês (ciclo) seguinte. Dessa forma, este tópico traz a junção da análise dos fatores descritos na discussão anterior, pois todos eles fazem parte da construção da fidelidade.

Identificou-se que o nível geral de satisfação nas CCR é alto e considerando que a satisfação é um fator determinante na fidelização de qualquer empreendimento, entende-se que ainda haveria espaço para ampliar a fidelização dos consumidores. Tal fator também se liga às motivações indicadas por eles para permanecerem ou desistirem do projeto, manifestando seu grau de comprometimento, que se traduz em fidelidade (Baloglu, 2002). A Figura 3 apresenta os aspectos mais citados pelos consumidores quanto às motivações em permanecer na iniciativa. As frases destacadas e/ou palavras que tiveram mais incidência nas falas encontram-se em tamanho grande, ao passo que as palavras menos citadas aparecem em tamanho menor (Word Cloud).

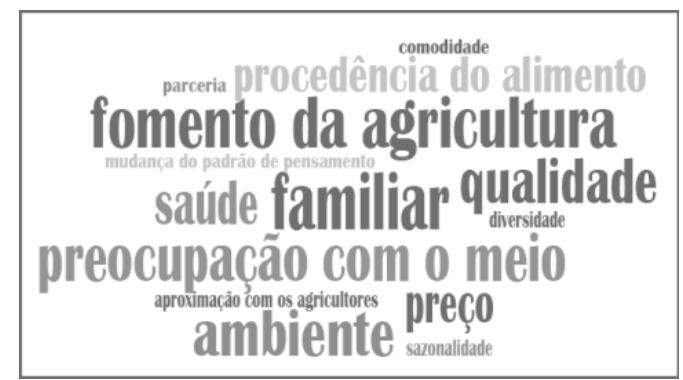

Figura 3. Motivações dos consumidores das CCR para continuarem participando da iniciativa (Word Cloud). Fonte: elaborado pelos autores (2019). 
Nesse sentido, constata-se que a principal motivação para continuar no projeto está ligada ao fomento da agricultura familiar, seguido da preocupação com o meio ambiente. Posteriormente, encontram-se aspectos que se referem à qualidade dos produtos a serem adquiridos (alimentos orgânicos e saudáveis), que induzem a pensar sobre a relação com a saúde. O conhecimento da origem e procedência do alimento também se mostra relevante, assim como o interesse mais utilitarista pelo benefício do acesso a alimentos com preços mais baixos, quando comparados aos demais mercados de alimentos orgânicos/agroecológicos.

Esses argumentos evidenciam a relação de fidelidade com a responsabilização dos consumidores, deixando clara a sensibilidade deles a respeito da vida dos agricultores e do ambiente que os cerca. Ainda, isso demonstra consciência deles em relação às práticas de consumo responsável, para promover mudanças mais intensas na sociedade e na natureza. Portanto, segundo a definição de Bendapudi e Berry (1997), configuram-se como consumidores que se preocupam em manter, para além das motivações econômicas, uma relação com os produtores baseada em motivações afetivas e psicológicas, ou seja, uma vez estabelecida a fidelidade como produto da relação entre satisfação e motivação, com base nas respostas se revela um importante grau de responsabilização dos consumidores, gerando atitudes de comprometimento que alimentam e são alimentadas por sua fidelização.

Por outro lado, alguns consumidores apontaram três principais aspectos que os fariam rever a sua permanência no projeto, como: (i) peso das cestas alto, dificultando o consumo de todos os alimentos e gerando desperdício; (ii) peso das cestas baixo, não atendendo à necessidade de quem consome mesmo com a lista de adicionais; (iii) pouca diversidade de produtos na lista de adicionais. Observa-se que o peso fixo das cestas e a baixa diversidade de produtos na lista de adicionais causam desconforto a esses consumidores, mesmo sendo poucos. Nesses casos, as pessoas alegam que gostariam de ter a opção de escolher os produtos que vêm na cesta, além de sugerirem a reformulação do tamanho e do peso. Entretanto, constata-se que esses incômodos não são significativos, uma vez que quando perguntados a respeito do nível de satisfação com a quantidade e diversidade de alimentos que recebem semanalmente, $30,7 \%$ dos consumidores classificaram como "muito boas" e 49,5\% como "boas".

O somatório desses pontos evidencia que há um processo de fidelização dos consumidores nas CCR. A maioria relata que, diante da sua experiência, a probabilidade de continuar participando seria alta e muito alta, totalizando 97\% das respostas (Figura 4). Esse dado contribui para as atitudes de comprometimento com a forma observada de como eles lidam com os produtos que recebem e o que pensam dessa inciativa. Além disso, a experiência tem sido satisfatória, o que pode levar à fidelização dos consumidores, porque mesmo que houvesse algumas contestações quanto aos aspectos citados anteriormente, todos estavam fazendo o possível para que o projeto se consolidasse e se expandisse.

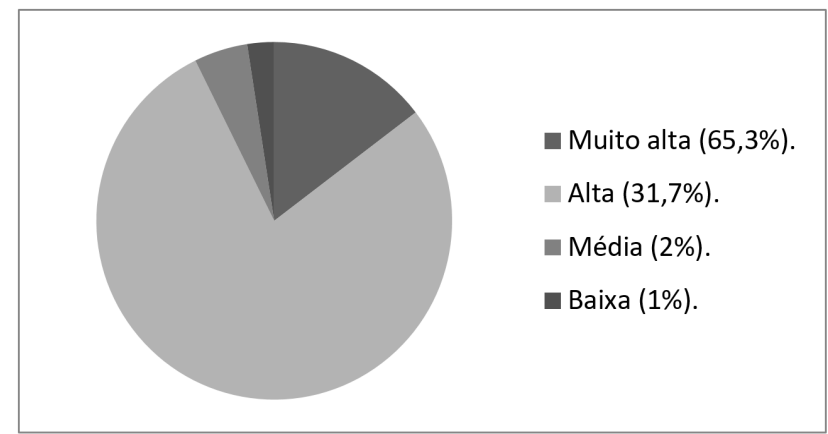

Figura 4. Probabilidade dos consumidores continuarem participando das CCR. Fonte: elaborado pelos autores (2019).

\section{Conclusões}

O projeto das CCR, por ser um modelo de venda direta de alimentos orgânicos/agroecológicos, é um ambiente em potencial para ampliar as ações do marketing de relacionamento. Isso porque os consumidores e os agricultores demonstraram-se 
interessados no estreitamento de relações; há consciência, por parte de muitos consumidores, do consumo responsável (responsabilização), no sentido de procurarem compreender a proposta das CCR e trazerem questões como a preocupação com os agricultores em torno da cadeia produtiva e o fomento à agricultura local de base agroecológica. Notam-se comprometimento coletivo geral em torno do projeto, no cumprimento das ações propostas no termo de responsabilidades e interesse em buscar alternativas para que o projeto se consolide e se expanda. Um projeto que nasce com 27 cestas semanais e atinge mais de 400 cestas 2,5 anos depois evidencia que consumidores e agricultores estão realizando o propósito de expansão.

A maioria dos consumidores está satisfeita com a experiência, não obstante a presença de algumas questões pontuais. Conclui-se que essa maioria tem fidelidade às $C C R$, visto que se demonstra comprometida e satisfeita, além de interessada em continuar participando da iniciativa. Sua busca por alimentos de qualidade orgânica, diferenciados, saudáveis e de proximidade com agricultores, gerou uma aproximação dos consumidores com a produção familiar agroecológica. Nesse processo em que se revelam altamente satisfeitos, evidenciamse crescente responsabilização, comprometimento e fidelização com a proposta das CCR. Nele, agricultores e consumidores intercambiam alimentos e valores imateriais, como reciprocidade, solidariedade e cooperação.

Acrescenta-se que, com os dados levantados neste trabalho, ainda há muitas possibilidades de pesquisa, como analisar e comparar a satisfação entre as diferentes CCR, procurando identificar quais os principais problemas de cada uma; analisar o nível de envolvimento dos consumidores de cada CCR e identificar como isso ocorre; compreender as dinâmicas de planejamento da produção para atender às CCR visando ampliar a satisfação dos consumidores.

Finalmente, considera-se muito importante ampliar formas de comercialização de venda direta de alimentos orgânicos/agroecológicos como as CCR, baseadas em ações de marketing de relacionamento. Este se apresentou como uma estratégia para os agricultores familiares fortalecerem e integralizarem ações necessárias para uma gestão compartilhada com os consumidores, bem como para o alcance da corresponsabilização pelas práticas de produção, distribuição e consumo.

\section{Referências}

Baloglu, S. (2002). Dimensions of customer loyalty: Separating friends from well wishers. The Cornell Hotel and Restaurant Administration Quarterly, 43(1), 47-59.

Bendapudi, N., \& Berry, L. L. (1997). Customers' motivations for maintaining relationships with service providers. Journal of Retailing, 73(1), 15-37.

Berry, L. L. (2001). Descobrindo a essência do serviço: os novos geradores de sucesso sustentável nos negócios. Rio de Janeiro: Qualitymark.

Birochi, R., Rover, O., \& Schultz, G. (Orgs.). (2019). Alimentos bons, limpos e justos da agricultura familiar brasileira. Florianópolis: Letras Contemporâneas.

Brasil. (2006, julho 24). Lei n 11.326, 24 de julho de 2006. Estabelece as diretrizes para a formulação da Política Nacional da Agricultura Familiar e Empreendimentos Familiares Rurais. Diário Oficial [da] República Federativa do Brasil, Brasília.

Buck, D., Getz, C., \& Guthman, J. (1997). From farm to table: The organic vegetable commodity chain of Northern California. Sociologia Ruralis, 37(1), 3-20. http://dx.doi.org/10.1111/1467-9523.00033

Darolt, M. R. (2013). Circuitos curtos de comercialização de alimentos ecológicos: reconectando produtores e consumidores. In Agroecologia: práticas, mercados e políticas para uma nova agricultura (pp. 139-170). Curitiba: Kairós.

Darolt, M. R., Lamine, C., \& Brandemburg, A. (2013). A diversidade dos circuitos curtos de alimentos ecológicos: ensinamentos do caso brasileiro e francês. Revista Agriculturas, 10(2), 8-13.

Fantini, A., Rover, O. J., Chiodo, E., \& Assing, L. (2018). Agroturismo e circuitos curtos de comercialização de alimentos orgânicos na Associação "Acolhida na Colônia"-SC/Brasil. Revista de Economia e Sociologia Rural, 56(3), 517-534. 
Florianópolis. Secretaria Municipal de Turismo, Tecnologia e Desenvolvimento Econômico. (2019). História. Recuperado em 3 de abril de 2019, de http://www.pmf.sc.gov.br/entidades/turismo/index.php?cms=historia

Fornell, C. (1992). A national customer satisfaction barometer: the Swedish experience. Journal of Marketing, 56(1), 6-21.

França, C. G., Grossi, M. E. D., \& Vicente, P. (2009). O censo agropecuário 2006 e a agricultura familiar no Brasil. Brasília: MDA.

Gazolla, M., \& Schneider, S. (2017). Cadeias curtas e redes agroalimentares alternativas: negócios e mercados da agricultura familiar. Porto Alegre: Editora da UFRGS.

Gelbcke, D., Rover, O., Brightwell, M., Silva, C., \& Viegas, M. A. (2019). “proximidade” nos circuitos de abastecimento de alimentos orgânicos da Grande Florianópolis - SC - Brasil. Estudos Sociedade e Agricultura, 26(3), 540-560. http://dx.doi.org/10.36920/esa-v26n3-3.

Gliessman, S. R., \& Rosemeyer, M. (2009). The conversion to sustainable agriculture: principles, processes, and practices. Boca Raton: CRC Press.

Goodman, D., \& Goodman, M. (2009). Alternative food networks. International Encyclopedia of Human Geography, 3, 208-220.

Guthman, J. (2004). The trouble with 'organic lite'in California: a rejoinder to the 'conventionalisation'debate. Sociologia Ruralis, 44(3), 301-316.

Instituto Brasileiro de Defesa do Consumidor - IDEC. (2012). Rota dos orgânicos. Revista do IDEC, 162, 20-23.

Instituto Brasileiro de Geografia e Estatística - IBGE. (2018a). Censo de 2018: população estimada, Santa Catarina. Recuperado em 8 de abril de 2019, de https://cidades.ibge.gov.br/brasil/sc/panorama

Instituto Brasileiro de Geografia e Estatística - IBGE. (2018b). Censo de 2018: população estimada, Florianópolis, Santa Catarina. Recuperado em 14 de fevereiro de 2019, de https://cidades.ibge.gov.br/brasil/sc/florianopolis/panorama

IPD Orgânicos. (2011). Pesquisa: o mercado brasileiro de produtos orgânicos. Curitiba: IPD.

Johnson, M. D., \& Fornell, C. (1991). A framework for comparing customer satisfaction across individuals and product categories. Journal of Economic Psychology, 12(2), 267-286.

Johnson, M. D., Gustafsson, A., Andreassen, T. W., Lervik, L., \& Cha, J. (2001). The evolution and future of national customer satisfaction index models. Journal of Economic Psychology, 22(2), 217-245.

Kotler, P., \& Armstrong, G. (2007). Princípios de marketing. São Paulo: Person Prentice Hall.

Manzato, A. J., \& Santos, A. B. (2012). A elaboração de questionários na pesquisa quantitativa (pp. 1-17). Departamento de Ciência de Computação e Estatística, Instituto de Biociências, Letras e Ciências Exatas, Universidade Estadual Paulista.

Marescotti, A. (2006). Le dimensioni della tipicità dei prodotti agroalimentari: guida per la Valorizzazione dei Prodotti Agroalimentari Tipici (concetti, metodi e strumenti). Manuale.

Niederle, P. A. (2013). Construção social de mercados e novos regimes de responsabilização no sistema agroalimentar. Agriculturas, 10, 4-8.

Organics Brasil. (2016). Organics Brasil mostra tendências do setor em congresso na Alemanha. São Paulo: Organics Brasil Imprensa.

Petrini, C. (2009). Slow Food: princípios da nova gastronomia. In C. Petrini, Slow food: princípios da nova gastronomia. São Paulo: Senac.

Portilho, F. (2009). Novos atores no mercado: movimentos sociais econômicos e consumidores politizados. Política \& Sociedade, 8(15), 199-224.

Preiss, P., Charão-Marques, F., \& Wiskerke, J. (2017). Fostering sustainable urban-rural linkages through local food supply: a transnational analysis of collaborative food alliances. Sustainability, 9(7), 1155.

Rodrigues, J. M. S. (2006). Gestão da satisfação e da fidelidade de consumidores: um estudo dos fatores que afetam a satisfação e a fidelidade no mercado de turismo (Dissertação de mestrado). Universidade Federal do Rio Grande do Norte, Natal.

Sul 21. (2019). Alimentos orgânicos geraram $R \$ 4$ bilhões de faturamento no ano passado. Recuperado em 4 de abril de 2019, de https://www.sul21.com.br/ultimas-noticias/geral/2019/04/alimentosorganicos-geraram-r-4-bilhoes-de-faturamento-no-ano-passado/ 
Universidade Federal de Santa Catarina - UFSC. Laboratório de Comercialização da Agricultura Familiar - LACAF. (2019). Recuperado em 14 de fevereiro de 2019, de https://lacaf.paginas.ufsc.br/celulasde-consumidores-responsaveis/

Vavra, T. G. (1997). Improving your measurement of customer satisfaction: a guide to creating, conducting, analyzing, and reporting customer satisfaction measurement programs. Milwaukee: ASQ Quality Press.

Viegas, M. T. (2016). Agroecologia e circuitos curtos de comercialização num contexto de convencionalização da agricultura orgânica (Dissertação de mestrado). Centro de Ciências Agrárias, Universidade Federal de Santa Catarina, Florianópolis.

Zamberlan, L., Sparemberger, A., Büttenbender, P.L., Wagner, A., \& Dahmer, I. T. (2008). O marketing de produtos orgânicos: um estudo exploratório a partir da opinião do consumidor. In Anais do $28^{\circ}$ Encontro Nacional de Engenheria de Produção. ABEPRO.

Zoldan, P. C., \& Mior, L. C. (2012). Produção orgânica na agricultura familiar de Santa Catarina em 2010 (Documentos Epagri, No. 239). Florianópolis: Epagri.

Submetido: 20/8/2019

Aceito: 15/10/2020

Sistema de Classificação do Journal of Economic Literature (JEL): Q12, Q13 e M31. 